\title{
Metal stresses affect the population dynamics of disease transmission in aquaculture species
}

\author{
Chung-Min Liao ${ }^{a, *, 1}$, Chao-Fang Chang ${ }^{\text {a,1 }}$, Ching-Hung Yeh ${ }^{\text {a, }}$, Szu-Chieh Chen ${ }^{\text {a }}$, \\ Kuo-Chin Chiang ${ }^{a}$, Chia-Pin Chio a , Berry Yun-Hua Chou ${ }^{\text {a }}$, Li-John Jou ${ }^{\text {a,b }}$, \\ Guang-Wen Lien ${ }^{c}$, Chieh-Ming Lin ${ }^{\text {a }}$, Huan-Hsiang Shen ${ }^{\text {a }}$, Guan-De Wu ${ }^{\text {d' }}$ \\ a Ecotoxicological Modeling Center, Department of Bioenvironmental Systems Engineering, National Taiwan University, \\ Taipei, Taiwan 10617 ROC \\ ${ }^{\mathrm{b}}$ Department of Biomechatronic Engineering, National Ilan University, Ilan, Taiwan 260 ROC \\ ${ }^{\mathrm{c}}$ Institute of Environmental Health, National Taiwan University, Taipei, Taiwan 10617 ROC \\ d Institute of Environmental Engineering, National Taiwan University, Taipei, Taiwan 10617 ROC
}

Received 14 December 2005; received in revised form 7 February 2006; accepted 28 February 2006

\begin{abstract}
The purpose of this study is to develop a mechanistic-based population dynamics of disease model to predict the effect of heavy-metal stresses on the susceptibility of the aquaculture species to pollution-associated infectious diseases. We link an ecologically based nonlinear epidemiological dynamics of host-parasite interactions with a deterministic susceptibilityinfectious-mortality (SIM) model to evaluate the host susceptibility to the waterborne metal stressors. We test the proposed pollution-associated population dynamics of disease model against published data regarding the effect of metal cations $\left(\mathrm{Cd}^{2+}\right.$, $\mathrm{Cu}^{2+}$, and $\mathrm{Hg}^{2+}$ ) on the susceptibility of hard clam (Meretrix lusoria) to birnavirus. We estimate stressor-specific transmission rate and basic reproductive number $\left(R_{0}\right)$, defined as the average number of secondary cases generated by one primary infected case, by fitting SIM model to published cumulative mortality data. The median pollution-associated $R_{0}$ estimates range from 0.99 to 1.03 . Here we show that the interplay of environmental chemical stressors and disease transmission explains the hostpathogen interactions presenting in the immunomodulating chemicals contaminated aquacultural systems, suggesting that predicting schemes will require the consideration of both environmental stressor variability and host size in aquaculture species populations. We suggest that in the future potential management actions the pathogen manipulation is better to be integrated to improve the on-line environmental stressors monitoring in aquacultural systems.
\end{abstract}

(C) 2006 Elsevier B.V. All rights reserved.

Keywords: Aquaculture; Density dependence; Disease; Ecotoxicology; Host-pathogen interactions; Epidemiology; Metal stress; Population dynamics

* Corresponding author. Tel.: +88622363 4512; fax: +88622362 6433.

E-mail address: cmliao@ntu.edu.tw (C.-M. Liao).

${ }^{1}$ The authors contributed equally to this paper that was initiated at the Fall 2005 Class "Simulation and Computation of Biosystems."

\section{Introduction}

Aquacultural practices frequently result in high population densities and other environmental stressors such as immunomodulating chemicals and numerous 
emerging diseases. It increases the risk of infection establishment and spread, resulting in serious economic or ecological problems in aquaculture species (Murray and Peeler, 2005). Great potential benefits would be gained from any appropriate management able to control the spread of the infectious diseases and eliminate it from the aquaculture species populations. On the other hand, mitigation of environmental stressors that increase the risk of host susceptibility to the spread of emerging disease, however, poses a significant challenge to the design of a realistic control strategy.

Sindermann (1990), LaPatra (1998), and Lafferty and Kuris (1999) have reviewed and evaluated comprehensively the pollution-associated diseases of marine fish and shellfish, indicating that there are several diseases for which a relationship with pollution seems evident. There are a number of other diseases for which a relationship with pollution is also indicated. Furthermore, there is some evidence that certain latent viral infections may be provoked into potency by environmental stressors involved in hostpathogen-environment interactions. These suggest that pollution stress can be a major contributing factor in the occurrence of some diseases in degraded habits.

There is evidence both from field observations and experimental studies of significant correlations between increased heavy-metal pollutants and increased mortality in aquaculture species. Hetrick et al. (1979) demonstrated that exposure to increased copper $(\mathrm{Cu})$ concentrations may be immunosuppressive by an increased susceptibility to infectious hematopoietic necrosis virus (IHNV) by rainbow trout (Oncorhynchus mykiss) exposed to $\mathrm{Cu}$ compared with control animals. Carballo et al. (1995) demonstrated that increased susceptibilities to Saprolegnia parasitica infection were observed for ammonia (71\%), $\mathrm{Cu}(57 \%)$, nitrite $(50 \%)$, and cyanide $(33 \%)$ in rainbow trout. Chou et al. (1998) demonstrated that an increase in heavy-metal stresses such as $\mathrm{Cu}$, cadmium $(\mathrm{Cd})$, mercury $(\mathrm{Hg})$, and zinc $(\mathrm{Zn})$ has a marked effect on the susceptibility of hard clam (Meretrix lusoria) to a low pathogenic infectious pancreatic necrosis virus (IPNV)-like aquaculture birnavirus infection. Chou et al. (1999) further indicated that an infectious pancreatic necrosis virus (IPNV) with only low pathogenicity could cause high mortality in groupers (Epinephelus sp.) when combined with heavy-metal stressors such as Zn, Cd, and Cu. Arkoosh et al. (1991, 1994, 1998, 2001) and Loge et al. (2005) revealed that pollution-associated immunodysfunction in juvenile Chinook salmon (Oncorhynchus tshawytscha) may lead to increased susceptibility to infection by a virulent marine pathogen Vibrio anguillarum.

Smith et al. (2005) suggested that the theoretical tools of ecology and epidemiology may be the cornerstone in constructing future program aimed at preventing and controlling infectious diseases throughout the world. Analysis of infectious disease ecology and host-pathogen interactions including pathogen transmission and disease manifestations are central to successful control strategies. From ecotoxicological point of view, environmental chemical stresses affect ecological endpoints such as intrinsic rates of increase, carrying capacity, and density dependence of populations involving in density-toxicant interactions (Sibly et al., 2000; Forbes et al., 2001; Hendriks et al., 2005). Here we intend to develop a framework focusing on constructing a mechanistic model by incorporating relevant principles from ecotoxicology into an epidemiological dynamics. We try to link the interplay relationships between disease transmission and environmental stressor variability that may contribute to a better understanding of the factors that ultimately affect recruitment of aquaculture species populations.

The purpose of this study is to construct a density and environmental stressor dependent host-pathogen model to evaluate the potential impact of heavy-metal stresses on the population dynamics of disease transmission in aquaculture species. To investigate the possible relationships between heavy-metals exposure and infectious disease mortality in aquaculture species, we focus on the disease-induced mortalities that occur before and after exposure to stressors that alter host susceptibility to infectious disease. The mortality profiles are based on two serial two-step processes involving exposure to heavy metals and then pathogen as well as exposure to pathogen and then heavy metals. The available data are adopted from the published laboratory disease challenge studies.

\section{Materials and methods}

\subsection{Modeling effects of environmental stress and epidemic on host population}

We derive a nonlinear population model to take into account ecologically, toxicologically, and epidemiologically relevant factors in aquacultural systems. The proposed model indicates a strong correspondence between transmission of infectious disease and variability of metal stressors. To address this issue, we incorporate standard ecotoxicological theory for chemical exposure into an epidemiological framework. 
We begin with an analysis of the dynamics of hostpathogen interactions in a homogeneous host population subjected to an environmental chemical stress of exposed concentration $C$. We do this by studying the ability of a lethal waterborne pathogen with the exposed concentration-dependent virulence $\alpha(C)$ and the transmissibility $\beta(\mathrm{C})$, to invade an aquaculture species population in a polluted aquacultural system. The waterborne pathogen spreads in an epidemic fashion throughout each generation before reproductive maturity is attained. The survivors then go on to reproduce, each producing on average offspring characterized by a population growth rate as a function of exposed concentration $(\lambda(C))$ that survive to emerge as adults at the start of the next generation (Anderson and May, 1991). The numbers of adults in successive generations could be characterized by a first-order nonlinear difference equation (Anderson and May, 1991),

$N(t+1)=\lambda(C) N(t)(1-I(N(t)))$,

where $N(t+1)$ and $N(t)$ are the population size in generations of $t$ and $t+1$ (number individual or denotes as ind), $\lambda(C)$ is the exposed concentration-dependent finite rate of increase or is called the asymptotic population growth rate (ind ind ${ }^{-1}$ day $^{-1}$ ), and $I(N(t))$ is the fraction of the population infected by the epidemic in generation $t$. The $\lambda(C)$ is the analogy of " $r$," the intrinsic rate of increase: $r(C)=\ln \lambda(C)$. The fraction of surviving to reproduce is $1-I$ in that the fraction $I$ is given by a simple extension of the Kermack-McKendrick (K\&M) model (Anderson and May, 1991). Here we modified K\&M model to a more appropriate form to include the effect of $C$,

$1-I=\exp \left(-I N(t) / N_{\mathrm{T}}(C)\right)$,

where $N_{\mathrm{T}}(C)$ is an exposed concentration-dependent threshold population size and can be determined by the transmissibility, $\beta(\mathrm{C})$, and the virulence, $\alpha(\mathrm{C})$ of the pathogen as: $N_{\mathrm{T}}(C)=\alpha(C) / \beta(C)$. If $N(t)$ is below threshold magnitude $\left(N(t)<N_{\mathrm{T}}(C)\right)$, the pathogen cannot spread: $I=0$, whereas $N(t)$ is above threshold $\left(N(t)>N_{\mathrm{T}}\right.$ $(C)$ ), the pathogen dose spread: $I \neq 0$. The K\&M epidemic model has been extensively analyzed and reviewed in the mathematical literature (Diekmann et al., 1995).

A fundamental concept in epidemic dynamics is the basic reproductive number (Anderson and May, 1991), $R_{0}$, quantifying the transmissibility of any pathogen. $R_{0}$ is defined as the average number of secondary cases generated by a typical primary case at the start of the epidemic in an entirely susceptible population. In the absence of the effects of chemical stressors on host susceptibility, $R_{0}>1$ implies that the epidemic is spreading within a population and that incidence is increasing, whereas $R_{0}<1$ means that the disease is dying out. An average $R_{0}$ of 1 means the disease is in endemic equilibrium within the population. $R_{0}$ essentially determines the rate of spread of an epidemic and how intensive a policy will need to be to control the epidemic. In light of the concept of $R_{0}$, the total proportion of uninfected population during the epidemic $(1-I)$ is seen to depend only on pollution-associated $R_{0}$, $R_{0}(C)$, as described in Eq. (2) (Anderson and May, 1991),

$1-I=\exp \left(-R_{0}(C) I\right)$.

Eq. (3) is based on the theoretical relationship between epidemic $(I)$ and $R_{0}(C)$ assuming a homogeneous and unstructured population. We optimally fitted Eq. (3) to the plot of relationships between $I$ and $R_{0}$ based on Anderson and May (1991) for $R_{0}$ ranging from 0.98 to 5 by using a nonlinear regression technique, resulting in

$1-I=\exp \left(1.63-1.66 R_{0}(C)\right), 0.98<R_{0}(C)<5$,

$r^{2}=0.99$.

We note that for $R_{0}(C)>5,1-I=\exp \left(-R_{0}(C)\right) \lll 1$ (Swinton, 1998).

We summarize Eqs. (1)-(4) to obtain an expression to describe the effects of pollution-associated infectious disease on host density,

$N(t+1)=N(t) \exp \left(\ln \lambda(C)+1.63-1.66 R_{0}(C)\right)$,

$0.98<R_{0}(C)<5$.

On the other hand, for $R_{0}(C)>5, N(t+1)=N(t) \exp (r$ (C) $\left.-R_{0}(C)\right)$.

Time-dependent population size $N(t)$ in Eq. (1) is conventionally modeled by the well-known VerhulstPearl logistic equation (Tsoularis and Wallace, 2002), given by

$N(t+1)=N(t) \exp \left[r_{0}\left(1-\frac{N(t)}{K}\right)\right]$,

where $r_{0}$ is a parameter representing per capita growth rate defined as $1 / N \times \mathrm{d} N / \mathrm{d} t$, and $K$ is the population's carrying capacity (ind). Here we assume that environmental stressor affects population size $N$ by reducing the per capita growth rate $r_{0}(C)$ as a function of the exposure concentration $C$. In addition to an inhibition of the per capita growth rate $\left(r_{0}\right)$, chemical stressor and disease also reduce the carrying capacity $K\left(R_{0}, C\right)$ expressed as 
functions of $C$ and $R_{0}$. We analogize Eqs. (5) and (6) to estimate per capita growth rate $\left(r_{0}(C)\right)$ and carrying capacity $\left(K\left(R_{0}, C\right)\right)$ from key epidemiological parameter $\left(R_{0}(C)\right)$ (Gerber et al., 2005),

$K\left(R_{0}, C\right) \equiv \frac{\ln \lambda(C)+1.63}{R_{0}(C)}$,

$r_{0}(C) \equiv \ln \lambda(C)+1.63$.

Eqs. (7) and (8) describe the effects of environmental chemical stressor on the host susceptibility characterizing by $\lambda(C)$ and $R_{0}(C)$.

\subsection{Pollution-associated population dynamics of disease model}

Here we use a mechanistic model allowing us to explore the effects of environmental chemical stressor on the pollution-associated population dynamics of disease transmission. To achieve this purpose, we modify the standard susceptible-infectious-recovered (SIR) structure to a disease-induced mortality-based susceptible-infectious-mortality (SIM) model to provide a mechanistic bridge between theoretical models and empirical data. The SIR class of models is a cornerstone of ecological epidemiology providing a simple mechanistic model for microparasite dynamics (Anderson and May, 1991; Lafferty and Holt, 2003; Loge et al., 2005).

We denote the number of infectious host at time $t$ by $Y(t)$. The force of infection, $\lambda_{\mathrm{F}}$, that is the infection pressure experienced by one susceptible individual, is then given by $\lambda_{\mathrm{F}}=\beta(C) Y(t)$. We use a deterministic SIM model with homogeneous mixing to estimate the force of infection. The dynamics of the susceptible $(X)$, the infected $(Y)$ and the mortality state $(Z)$ for aquaculture species exposed to a pollution-associated disease can be described as

$$
\frac{\mathrm{d} X}{\mathrm{~d} t}=-\beta(C) Y X,
$$

$\frac{\mathrm{d} Y}{\mathrm{~d} t}=\beta(C) Y X-\alpha(C) Y$,

$\frac{\mathrm{d} Z}{\mathrm{~d} t}=\alpha(C) Y$.
After determining $\beta(C)$ and $\alpha(C)$, the pollutionassociated basic reproductive number $\left(R_{0}(C)\right)$ can be calculated using the formula (Anderson and May, 1991),

$R_{0}(C)=\frac{N(0) \beta(C)}{\alpha(C)}$,

where $N(0)$ is the initial host population size (ind).

Therefore, the carrying capacity in terms of disease parameter and environmental chemical stressor can be obtained as

$K\left(R_{0}, C\right)=\left(\frac{\alpha(C)}{\beta(C)}\right) \frac{(\ln \lambda(C)+1.63)}{N}$.

Once the interplay of environmental chemical-driven stress and disease dynamics is taken into account, a nonlinear population model that achieves this by explicitly taking into account epidemiological dynamics (i.e., changes in the abundance of susceptible host, per capita growth rate, and disease transmission rate) could all be reconstructed as

$$
\begin{aligned}
& N(t+1) \\
& \quad=N(t) \exp \left[(\ln \lambda(C)+1.63)\left(1-\frac{1.66}{\left(\frac{1.63+\ln \lambda(C)}{N \beta(C) / \alpha(C)}\right)}\right)\right] .
\end{aligned}
$$

The nonlinear nature of Eq. (14) revels that pollutionassociated population dynamics of disease model could be characterized in terms of chemical stressor concentration $(C)$, pollution-associated population growth rate $(\lambda(C))$, transmissibility $(\beta(C))$, and disease-specific mortality rate $\alpha(C)$. Eqs. (9)-(11) thus provide a simplified yet fully specified mechanistic model for the pollution-associated dynamics of disease transmission. Eqs. (9)-(11) can link Eq. (14) to represent a novel and quantitative analysis of the effects of environmental stressor on host susceptibility and subsequently modulation of disease dynamics in aquaculture species populations.

\subsection{Model calibration}

Thanks to the excellent published data of the cumulative incidence of mortality, the model (Eqs. (9)(11) and (14)) can be tested and evaluated. The published data is adopted from the laboratory disease challenge experiments in studying the effects of heavy-metal cations on the susceptibility of hard clam ( $M$. lusoria) to clam birnavirus infection (Chou et al., 1998). Isshiki et 
al. (2001) have extensively reviewed the infectivity of aquabirnavirus to various marine fish species.

Chou et al. (1998) indicated that the hard clam $M$. lusoria that are cultured in Taiwan have suffered high mortality each spring/summer since 1969. Environmental factors such as pollution and infectious disease have been implicated, yet no single factor has been shown to lead directly to larger scale death of the cultured hard clam. Chou et al. (1998) conducted two experiments to examine the effects of heavy metals on the disease transmission in hard clam. In experiment I (denoting as $\mathrm{V}+$ metal ion), a group of 60 clams was immersed in birnavirus solution (CV-TS-1 virus) for $24 \mathrm{~h}$ and subsequently exposed to one of the heavy metals of $\mathrm{Zn}^{2+}, \mathrm{Cd}^{2+}, \mathrm{Cu}^{2+}$, and $\mathrm{Hg}^{2+}$. In experiment II (denoting as metal ion $+\mathrm{V}$ ), clams were exposed to one of the heavy metals for 7 days and then infected with the CVTS-1 virus in that controls were only exposed to heavy metals. CV-TS-1 is an aquaculture birnavirus that can be isolated from the gills of hard clam in southern Taiwan and is serologically similar to Ab type of IPNV that is a low pathogenicity to fish (Lo et al., 1988). The major results in experiment I indicated that cumulative mortalities of clams were $20-50 \%$ in most of the experimental groups after 5 weeks, whereas in experiment II, the survival time shortened and the mortalities ranged from $65 \%$ to $90 \%$.

The proposed model was applied to cumulative mortality data to obtain estimates of the model parameters of $\beta(C), \alpha(C)$, and $R_{0}(C)$. Practically, McCallum et al. (2001) have rigorously outlined the method to estimate transmission rate. We first discretely estimated the $\lambda_{\mathrm{F}}$ by fitting Eq. (9) to the cumulative mortality curves by $\Delta S=(1-\Delta M(\%)) N$ where $M(\%)$ is the percent of cumulative mortality. By the definition of $\beta(C)=\lambda_{\mathrm{F}} / Y=\lambda_{\mathrm{F}} /(M(\%) N)$, the stressor-specific transmission rate $(\beta(C))$ can be estimated. We then estimate simultaneously the mortality-based $R_{0}(C)$ and $\alpha(C)$ by optimal fitting $R_{0}(C)=\beta(C) N / \alpha(C)$ to published mortality curves at conditions of $N=60$ and constant $\beta(C)$ estimates. Finally, the relationships of $\beta(C)-C$ and $\alpha(C)-C$ over a wide range of exposed metal ion concentrations in a specific functional form can be characterized.

Optimal statistical models were selected on the basis of least squared criterion from a set of generalized linear and nonlinear autoregression models provided by TableCurve 2D package (Version 5, AISN Software Inc., Mapleton, OR, USA) fitted to the data. A value of $p<0.05$ was judged significant. We used a Monte Carlo simulation to quantify our uncertainty concerning transmissibility $(\beta)$ and disease-specific mortality rate.
We used the Kolmogorov-Smirnov (K-S) statistics to optimize the goodness-of-fit of distributions. We employed Crystal Ball software (Version 2000.2, Decisioneering, Inc., Denver, CO, USA) to analyze data and to estimate distribution parameters. For this study, 10,000 iterations are sufficient to ensure stability of results.

\section{Results}

\subsection{Effects of metal stress on host susceptibility to infection}

The estimated median transmission rates are 0.026 $\left(\mathrm{V}+0.1 \mathrm{ppm} \mathrm{Cu}^{2+}\right)$ and $0.018\left(0.1 \mathrm{ppm} \mathrm{Cu}^{2+}+\mathrm{V}\right)$, $0.0085\left(\mathrm{~V}+0.005 \mathrm{ppm}^{\mathrm{H}} \mathrm{Hg}^{2+}\right)$ and $0.0197(0.005 \mathrm{ppm}$ $\left.\mathrm{Hg}^{2+}+\mathrm{V}\right)$, and $0.0077\left(\mathrm{~V}+0.05 \mathrm{ppm} \mathrm{Cd}^{2+}\right)$ and 0.0127 day $^{-1}$ ind $^{-1}\left(0.05 \mathrm{ppm} \mathrm{Cd}^{2+}+\mathrm{V}\right)$, respectively, for experiments I and II. The results indicate that the estimated stressor-specific transmission rates are higher in the experiment II settings than that of experiment I, but not for $\mathrm{Cu}^{2+}$-virus system (Fig. 1 and Table 1). On the other hand, the median mortality rates are estimated to be $1.56\left(\mathrm{~V}+0.1 \mathrm{ppm} \mathrm{Cu}^{2+}\right)$ and $1.06(0.1 \mathrm{ppm}$ $\left.\mathrm{Cu}^{2+}+\mathrm{V}\right), \quad 0.52\left(\mathrm{~V}+0.005 \mathrm{ppm} \mathrm{Hg}^{2+}\right)$ and 1.16 $\left(0.005 \mathrm{ppm} \mathrm{Hg}^{2+}+\mathrm{V}\right)$, and $0.47\left(\mathrm{~V}+0.05 \mathrm{ppm} \mathrm{Cd}^{2+}\right)$ and $0.73 \mathrm{day}^{-1}\left(0.05 \mathrm{ppm} \mathrm{Cd}^{2+}+\mathrm{V}\right)$, respectively, for experiments I and II (Fig. 1 and Table 1). Fig. 1 also depicts the fitted transmission and mortality rate functions in a range of metal ion concentrations based on the limited available data.

We estimate the pollution-associated basic reproductive number $\left(R_{0}(C)\right)$ by fitting a deterministic SIM model to the cumulative mortality data. The median values are approximately $0.99-1.03$ for both experiments I and II (Fig. 2) in that the highest $R_{0}(C)$ occurs at the condition of $0.05 \mathrm{ppm} \mathrm{Cu}^{2+}+$ virus $\left(R_{0}(C)=1.03\right)$. Our results also reveal that the epidemic will spread throughout the hard clam population when the mortality-based $R_{0}(C)$ estimate greater than 0.98 in a pollutionassociated disease environment. Data availability led us to model the effects of metal on the susceptibility of hard clam to birnavirus infection.

\subsection{Pollution-associated dynamics of disease with a density-dependent process}

The model predicts cumulative mortality profiles that were significantly fitted with the published cumulative mortality data at selected experimental settings for experiments I and II (Fig. 3). The stressor-specific intrinsic rate of increase $(r(C))$ is estimated by fitting the 

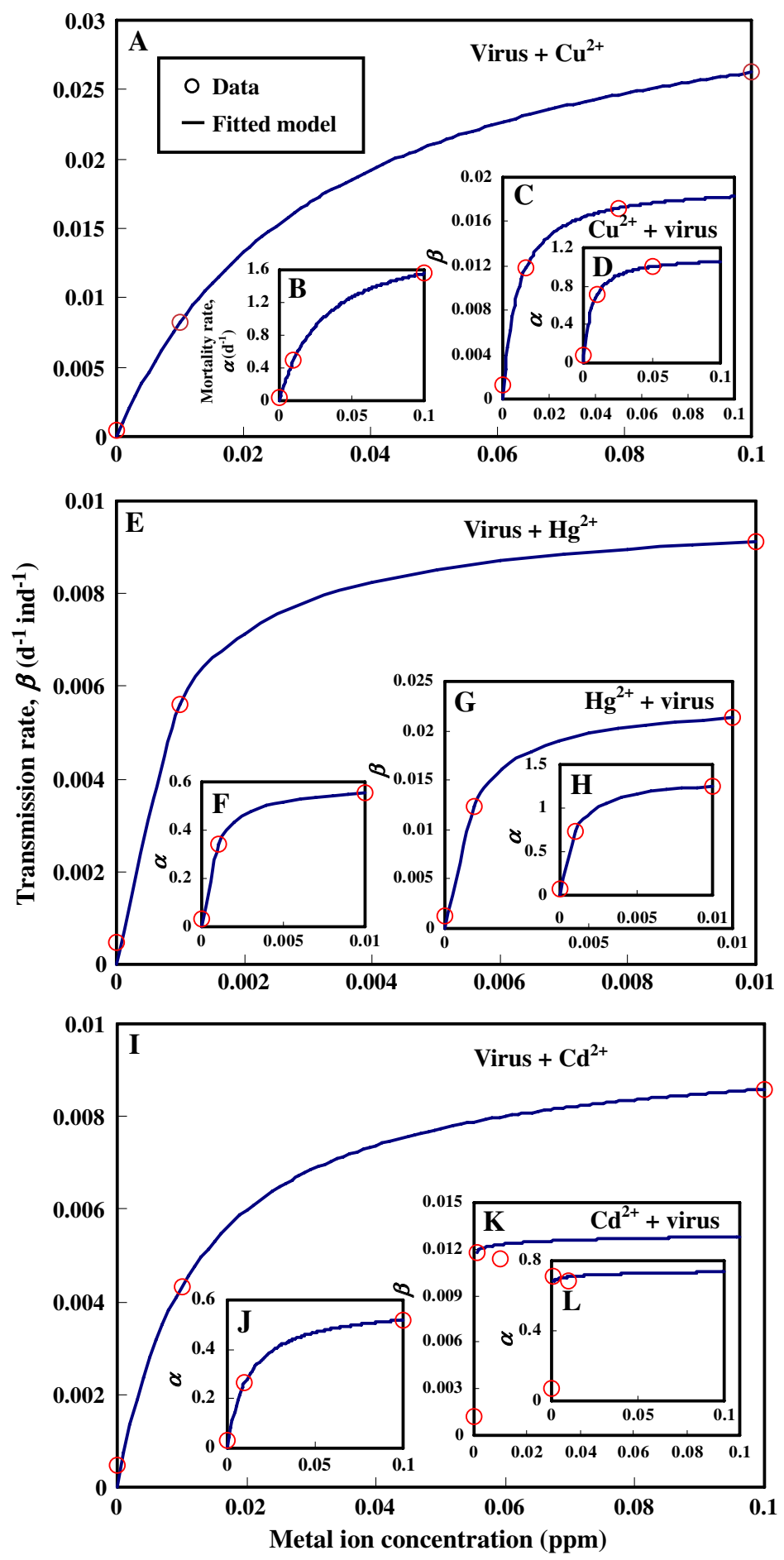

Fig. 1. Estimated stressor-specific disease transmission rate for virus added $\mathrm{Cu}^{2+}, \mathrm{Hg}^{2+}, \mathrm{Cd}^{2+}(\mathrm{A}, \mathrm{E}, \mathrm{I}), \mathrm{for} \mathrm{Cu}^{2+}, \mathrm{Hg}^{2+}, \mathrm{Cd}^{2+}$ added virus $(\mathrm{B}, \mathrm{F}, \mathrm{J})$ and mortality rate for virus added $\mathrm{Cu}^{2+}, \mathrm{Hg}^{2+}, \mathrm{Cd}^{2+}(\mathrm{C}, \mathrm{G}, \mathrm{K})$, for $\mathrm{Cu}^{2+}, \mathrm{Hg}^{2+}, \mathrm{Cd}^{2+}$ added virus (D, H, L) profiles as the function of metal ion concentration based on the published cumulative mortality data obtained from the laboratory disease challenge experiments (Chou et al., 1998) in that the best fitted models for different experimental settings are shown in Table 1. 
Table 1

Estimated functional forms of stressor-specific transmission and mortality rates associated with their median (95\% CI) estimates based on the published mortality data obtained from the laboratory disease challenge experiments (Chou et al., 1998)

\begin{tabular}{|c|c|c|c|c|c|c|c|}
\hline \multicolumn{4}{|c|}{ Transmission rate, $\beta\left(\right.$ day $^{-1}$ ind $\left.^{-1}\right)$} & \multicolumn{4}{|c|}{ Mortality rate, $\alpha\left(\right.$ day $\left.^{-1}\right)$} \\
\hline$a$ & $b$ & $r^{2}$ & Median $(95 \% \mathrm{CI})$ & $a$ & $b$ & $r^{2}$ & Median $(95 \% \mathrm{CI})$ \\
\hline \multicolumn{8}{|c|}{ Virus $+0.1 \mathrm{ppm} \mathrm{Cu}^{2+\mathrm{a}}$} \\
\hline 0.0347 & 898.094 & 0.999 & $0.0262(0.0238-0.0287)$ & 2.033 & 16.042 & 0.999 & $1.556(1.409-1.701)$ \\
\hline \multicolumn{8}{|c|}{$0.1 \mathrm{ppm} \mathrm{Cu}^{2+}+$ virus $^{\mathrm{a}}$} \\
\hline 0.0194 & 8024.233 & 0.988 & $0.0183(0.0149-0.021)$ & 1.118 & 154.868 & 0.987 & $1.057(0.869-1.234)$ \\
\hline \multicolumn{8}{|c|}{ Virus $+0.005 \mathrm{ppm} \mathrm{Hg}^{2+\mathrm{a}}$} \\
\hline 0.00980 & $136,136.233$ & 0.994 & $0.00852(0.00736-0.00960)$ & 0.594 & 2264.239 & 0.994 & $0.517(0.444-0.582)$ \\
\hline \multicolumn{8}{|c|}{ 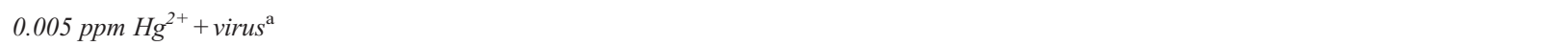 } \\
\hline 0.0231 & $49,903.576$ & 0.992 & $0.0197(0.0165-0.0226)$ & 1.357 & 874.249 & 0.992 & $1.161(0.970-1.337)$ \\
\hline \multicolumn{8}{|c|}{ Virus $+0.05 \mathrm{ppm} \mathrm{Cd}^{2+\mathrm{a}}$} \\
\hline 0.00963 & 8495.577 & 0.993 & $0.00774(0.00632-0.00907)$ & 0.581 & 143.429 & 0.993 & $0.468(0.380-0.548)$ \\
\hline \multicolumn{8}{|c|}{$0.05 \mathrm{ppm} \mathrm{Cd}^{2+}+$ virus $^{\mathrm{b}}$} \\
\hline 0.0127 & 0.000199 & 0.994 & $0.0127(0.0116-0.0121)$ & 0.763 & 0.0120 & 0.994 & $0.727(0.697-0.758)$ \\
\hline
\end{tabular}

${ }^{\mathrm{a}}$ Best fitted model: $y=a(1-1 /(1+a b x))$ (see Fig. 1A-J).

b Best fitted model: $y=a+b \ln x$ (see Fig. $1 \mathrm{~K}-\mathrm{L}$ ).

exponential growth model: $\ln (N(t+1) / N(t))=r(C)$ to the data (Fig. 4).

Population dynamics of disease differed significantly from different experimental settings of $\mathrm{V}+$ metal ion and metal ion $+V$. Our results indicate that the effective times that cause $50 \%$ population mortality (ET50) are more shortened in metal ion $+\mathrm{V}$ settings than that of $\mathrm{V}+$ metal ion. The results show that ET50s are around 6 $\left(0.1 \mathrm{ppm} \mathrm{Cu}^{2+}+\mathrm{V}\right)$ and 9 days $\left(\mathrm{V}+0.1 \mathrm{ppm} \mathrm{Cu}^{2+}\right), 20$ $\left(0.05 \mathrm{ppm} \mathrm{Cd}^{2+}+\mathrm{V}\right)$ and 37 days $\left(\mathrm{V}+0.05 \mathrm{ppm} \mathrm{Cd}^{2+}\right)$, and $11\left(0.005 \mathrm{ppm} \mathrm{Hg}^{2+}+\mathrm{V}\right)$ and 46 days $(\mathrm{V}+$ $\left.0.005 \mathrm{ppm} \mathrm{Hg}^{2+}\right)$, respectively, based on the initial $N=60$ hard clams (Fig. 5). The pollution-associated disease dynamics experiences most different response curves in hard clam population exposed to viral infection in combination with environmental metal stressors (Fig. 6). Fig. 6 can also be used to predict the effective reduction in percent mortality for hard clam

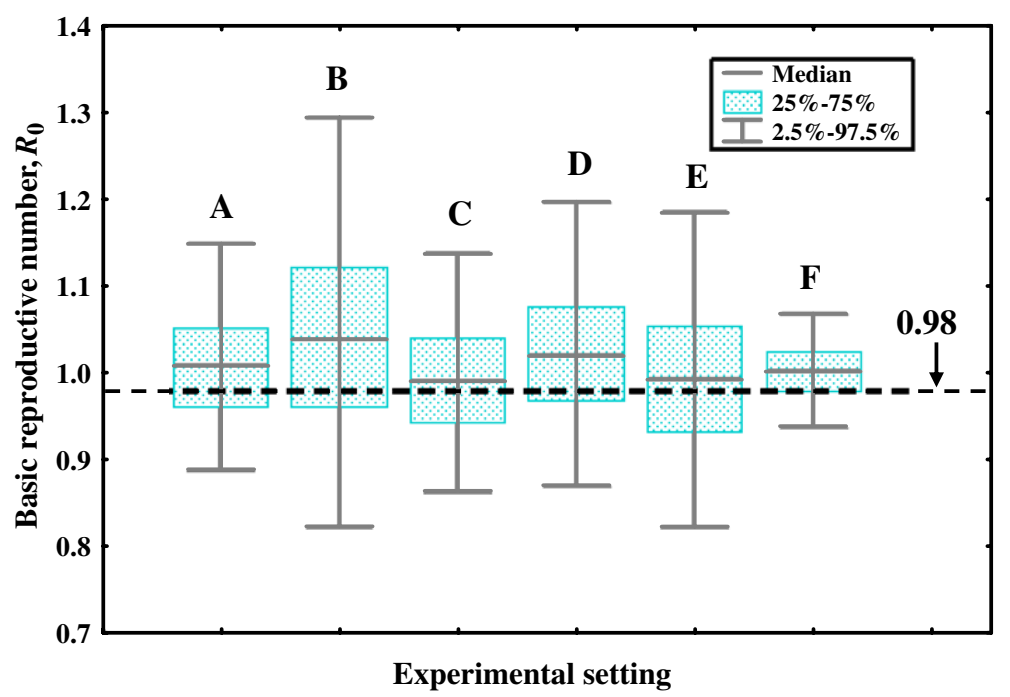

Fig. 2. Box and whisker plot representations of the basic reproductive number $\left(R_{0}\right)$ for different experimental settings. $(\mathrm{A}) \mathrm{V}+0.05 \mathrm{ppm} \mathrm{Cu}{ }^{2+},(\mathrm{B})$ $0.05 \mathrm{ppm} \mathrm{Cu}^{2+} \mathrm{V}$, (C) $\mathrm{V}+0.001 \mathrm{ppm} \mathrm{Hg}^{2+}$, (D) $0.005 \mathrm{ppm} \mathrm{Hg}^{2+}+\mathrm{V}$, (E) $\mathrm{V}+0.05 \mathrm{ppm} \mathrm{Cd}^{2+}$, and (F) $0.05 \mathrm{ppm} \mathrm{Cd}^{2+}+\mathrm{V}$ 


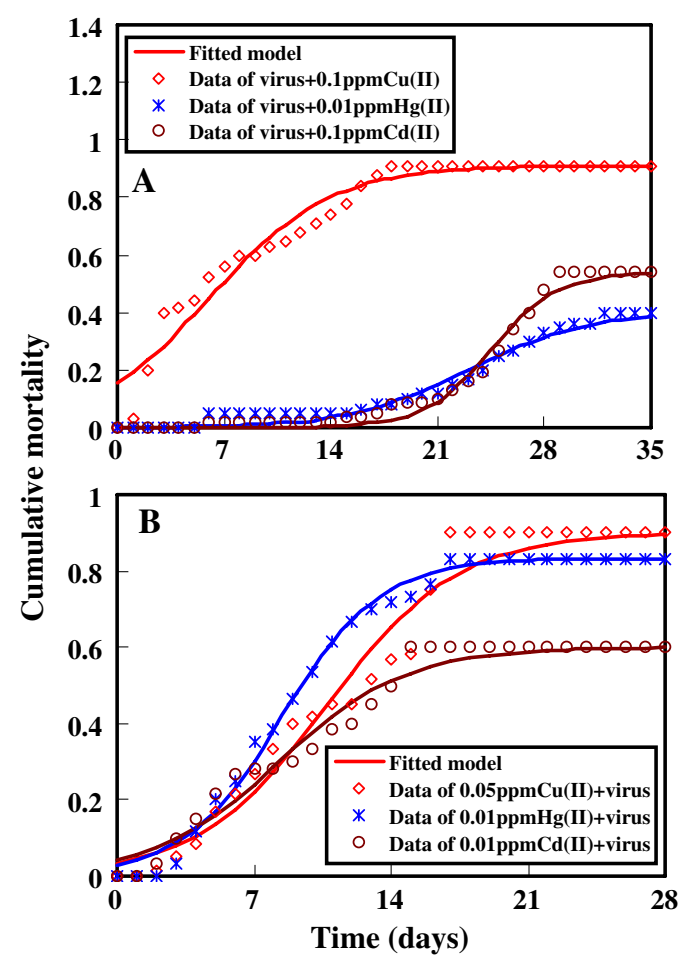

Fig. 3. Proposed pollution-associated population dynamics of disease model tested against the published cumulative data of (A) experiment I: virus + metal ion and (B) experiment II: metal ion+virus.

population continuous exposure to specific pollutionassociated disease settings in the condition of metal ion concentration ranging from 0.01 to $0.1 \mathrm{ppm}\left(\mathrm{V}-\mathrm{Cu}^{2+}\right.$ and $\left.\mathrm{V}-\mathrm{Cd}^{2+}\right)$ and $0.001-0.01\left(\mathrm{~V}-\mathrm{Hg}^{2+}\right)$ during residence times ranging from 0 to 100 days.
A sensitivity analysis is performed to show that the pollution-associated disease dynamics is density dependent (Fig. 7). Fig. 7 reveals that the higher the population number, the higher the cumulative incidence, and hence, the mortality in that the time to peak infection and mortality shortens is associated with a drop in the mortality along with a decrease in clam size. The result suggests that rearing size or density itself is sufficient to manipulate the level of disease from acute to chronic.

\section{Discussion}

\subsection{Impact of metal stressors on dynamics of disease transmission}

Our model supports the theory that in a hard clambirnavirus-metal stressor system, environmental metal stressor is an important determinant affecting population dynamics of disease transmission. It implicates that the control measures may be achieved through mitigation of not only pathogen virulence, but also chemical stressors in host-pathogen interactions that play a central role in determining the dynamics and persistence of aquaculture species populations.

Chou et al. $(1998,1999)$ suggested that in the metal ion + virus and virus + metal ion experiments, the immune system of fish/shellfish effectively eliminated the virus in most of the unstressed species. When the virus was not eliminated, even low virus levels were sufficiently high to cause death in most cases, whereas the increased susceptibility of fish/shellfish exposed to

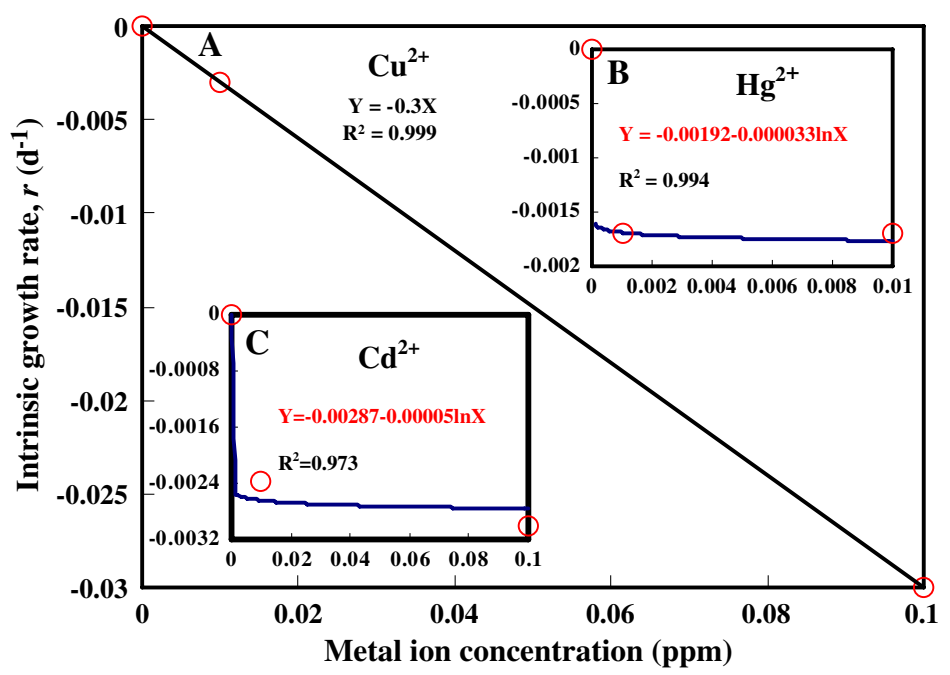

Fig. 4. Best fitted stressor-specific intrinsic growth rate profiles as a function of metal ion concentrations of $(\mathrm{A}) \mathrm{Cu}^{2+}$, (B) $\mathrm{Hg}^{2+}$, and $(\mathrm{C}) \mathrm{Cd}^{2}+$, respectively, based on the published cumulative mortality data (Chou et al., 1998). 

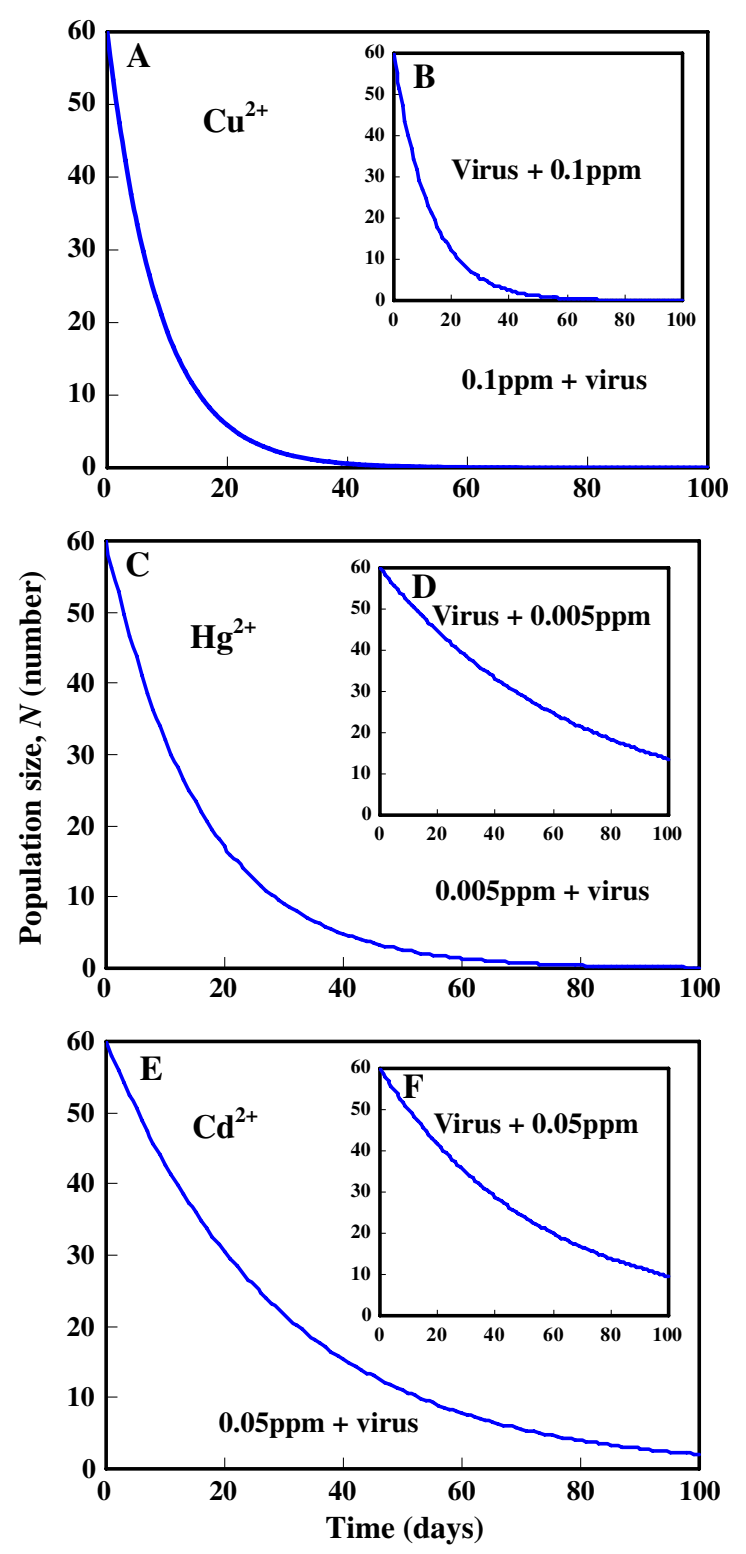

Fig. 5. Simulations of pollution-associated population dynamics of disease in different disease challenge experimental settings based on the initial hard clams number=60: (A) $0.1 \mathrm{ppm} \mathrm{Cu}^{2+}+$ virus, (B) virus + $0.1 \mathrm{ppm} \mathrm{Cu}^{2+}$, (C) $0.005 \mathrm{ppm} \mathrm{Hg}^{2+}+$ virus, (D) virus $+0.005 \mathrm{ppm} \mathrm{Hg}^{2+}$, (E) $0.05 \mathrm{ppm} \mathrm{Cd}^{2+}+$ virus, and (F) virus $+0.05 \mathrm{ppm} \mathrm{Cd}^{2+}$.

heavy metal was due to their incapability of eliminating the virus. These considerations support the theory that aquaculture species exposed to chemical stressors are immunosuppressed, and that this suppression may be associated with an increase in disease susceptibility and mortality. It results in the idea that immunosuppressed species may allocate greater energy and resources for defending themselves against infection and reducing resources for other vital physiological functions such as growth and reproduction (Arkoosh et al., 1998).

In light of the effect of immunomodulating chemicals on immunocompetence of aquaculture species, host immunity has a key role in the nonlinear population dynamics of disease transmission. In the future work, we may use a nonlinear population model that takes into account immunity and pollution-associated disease transmission to show the relationships between disease transmission and environmental stressor variability. Here, we have shown that the existence of immunomodulating heavy metals that increases in disease transmission resulting in increased susceptibility of aquaculture species to infections. Once the interplay of environmental stressors and disease dynamics is taken into account, clear evidence emerges for a role of environmental stressors variability in the dynamics of disease transmission.

\subsection{Effects of host density on pollution-associated disease epidemics}

There is accumulating empirical evidence that the density-dependent process may play a large part in spreading the disease among aquaculture species population. For instance, density dependence was detected in the spread of IPNV (Bebak-Williams et al., 2002a,b) and IHNV (Ogut and Reno, 2004) in rainbow trout as well as in the furunculosis epidemics in Chinook salmon (Ogut et al., 2004, 2005).

Density dependence and frequency dependence are familiar mechanisms in population biology to determine disease transmission (McCallum et al., 2001; Begon et al., 2002; Gerber et al., 2005). Swinton (1998) and McCallum et al. (2001) indicated that in discrete compact neighborhoods, numbers rather than densities are appropriate. A fish/shellfish population in a tank that is closed with infectious units and a homogeneous contact structure can be considered a perfect example of such a neighborhood (Begon et al., 2002). In the modeling of birnavirus transmission in hard clams, we used the simple SIM model with numbers to simulate CV-TS-1 epidemics. Hence, the proposed simple SIM model was capable of predicting the population dynamics of disease in aquaculture species population. Our model indicates that a decrease in host size causes a significant decrease in the mortality rate and an even larger decrease in the transmission coefficient. It suggests that host size or density is a key factor and should be evaluated carefully to decrease disease transmission in aquaculture species populations. Our proposed model provides an invaluable tool to control 

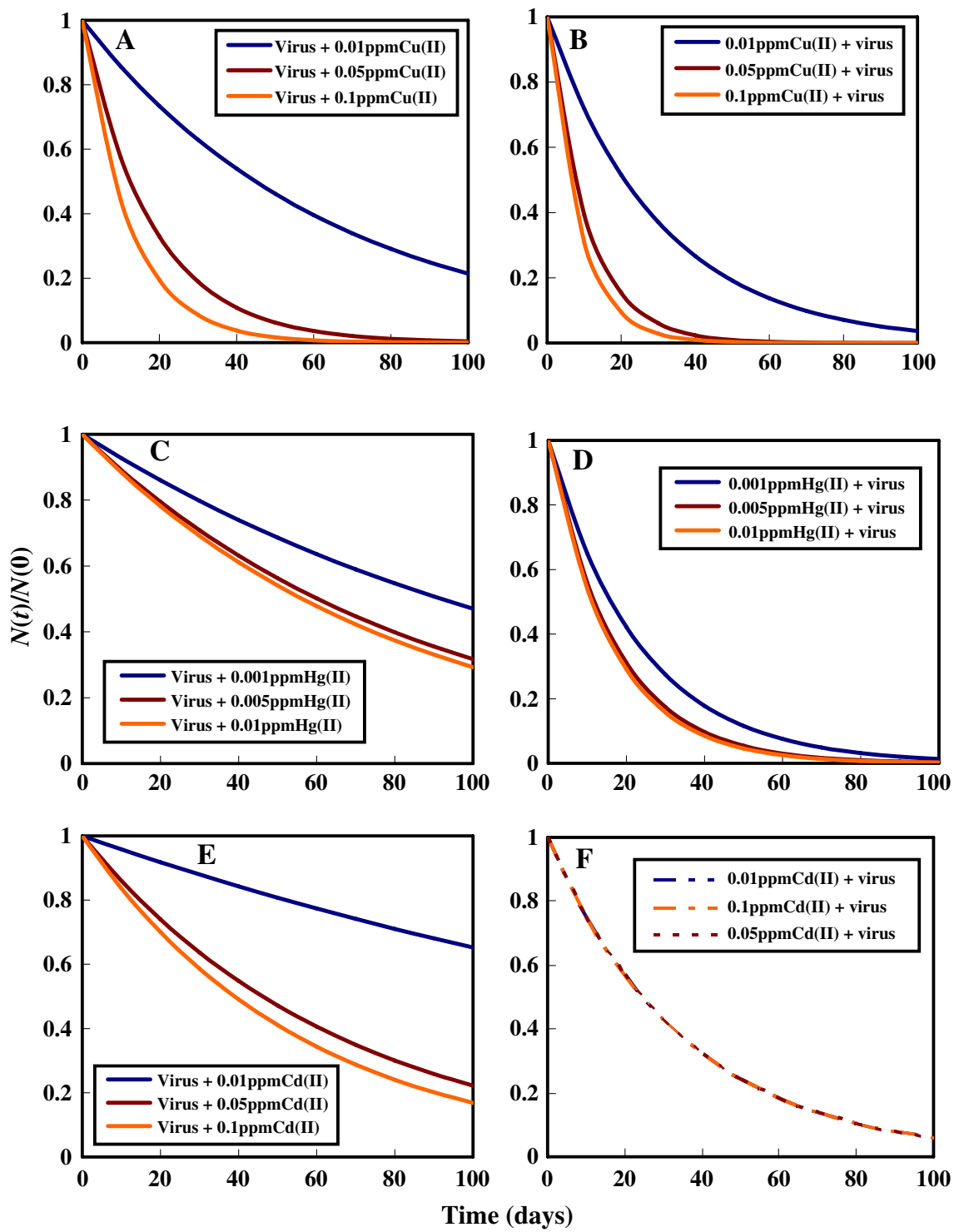

Fig. 6. Simulated response curves of pollution-associated population dynamics of disease in different experimental settings.

and eliminate diseases that could threaten the survival of aquaculture species in a pollution-associated disease environment.

The value of $R_{0}(C)$ for a pollution-associated infection with a population can be estimated from knowledge of the biological characteristics of the disease, such as host density or size, characteristics of immunomodulating chemicals, and rates of infection and host mortality. Some factors determining the magnitude of $R_{0}(C)$ are specific to the parasite itself (e.g., mechanisms of transfer and stability in the environment), whereas others are specific to the host (e.g., host density, size, species, behavior) or environ- ment (temperature, flow rate, water quality) (Ogut et al., 2004). Under the controlled conditions provided, effects of all parameters related to the disease-causing agent and the host are summarized under the parameter transmission coefficient $(\beta)$, which is essential in the calculation of $R_{0}(C)$. In our application, any reduction in the value of $R_{0}(C)$ below 0.98 will act to reduce disease prevalence and incidence to a level at which infection cannot be sustained and the pathogen will be eliminated from the population. Hence, the condition $R_{0}(C)=0.98$ in the hard clam-birnavirus-metal system indicates a transmission threshold below which the disease agent is unable to maintain itself within the host population. 


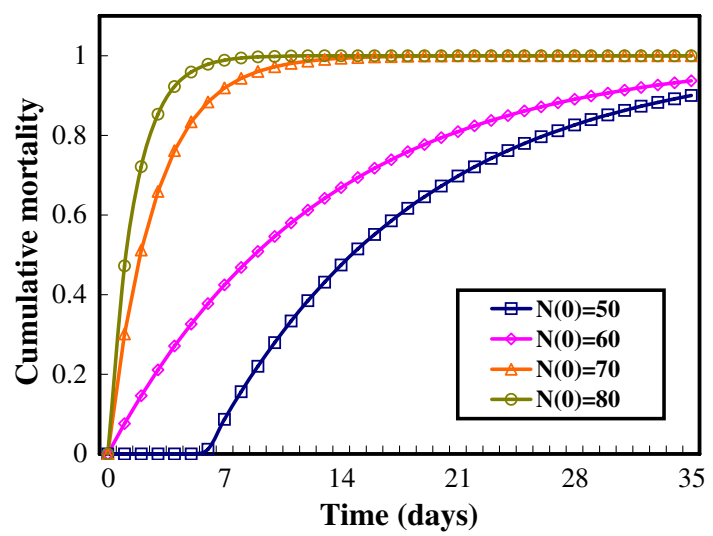

Fig. 7. Density-dependent cumulative mortality profiles in the experimental setting of virus $+0.1 \mathrm{ppm} \mathrm{Cu}^{2+}$ show that the higher the population size, the higher the cumulative incidence and, hence, the mortality.

Our results also indicate that the value of $N_{\mathrm{T}}$ is dynamic according to factors related to host, pathogen and environment. For example, in the hard clambirnavirus-metal system with virus $+0.1 \mathrm{ppm} \mathrm{Cu}^{2+}$ (Fig. 7), larger than 50 animals could be required to initiate an epizootic. The value of $N_{\mathrm{T}}$ is important and could serve as a starting point optimal for aquaculture species under the defined conditions (Ogut et al., 2004).

\subsection{Implications in management strategies}

Chemical stressors may affect population size $N$ by reducing the growth rate $r_{0}(C)$ as a function of the exposure concentration $C$. Here the experimental data we adopted were conducted and measured by using adult hard clams (3 months old). Therefore, we did not take into account the larval quality and survival. To explicitly assess the role of pollution-associated disease in analyses of growth/survival risks for aquaculture species of protection concern, information on host density dependence, pathogen $R_{0}(C)$, and probability of pathogen arrival will need to be included in conventional management models. Further management actions for aquaculture species exposed to pollutionassociated disease environment may involve manipulating environmental stressors to reduce the host susceptibility to infections. For such situations, a pollution-associated population dynamics of disease model explicitly will be essential to predict how much manipulation is necessary to increase population persistence. The interaction of selected immunomodulating chemicals with the regulation of immunologically and toxicologically relevant genes and force of infection associated with the dynamics of host-pathogen inter- actions within the pollution-associated infectious disease scenarios should also be included (Loge et al., 2005).

Our proposed approach represents an integration of relevant principles of ecology, toxicology, and epidemiology associated with the available data to date. It also provides a mechanistic-based quantitative representation of the potential magnitude of pollutionassociated disease-induced mortalities and the direction for future management of general aquaculture species. Future work should explicitly compare the predictability of models based solely on immunomodulating chemicals on intrinsic rate of increase and carrying capacity. Our results suggest that predicting schemes will require the consideration of both environmental stressor variability and the host size or density. Given that the time series on susceptible levels are rarely available, approaches presented here are crucial in the attempt to predict and anticipate the future size of outbreaks of emerging infectious diseases in aquaculture (Murray and Peeler, 2005). Therefore, to be integrated with susceptibility levels associated with pathogen manipulation in the future work is encouraged.

\section{References}

Anderson, R.M., May, R.M., 1991. Infectious Diseases of Humans: Dynamics and Control. Oxford University Press, New York, NY.

Arkoosh, M.R., Casillas, E., Clemons, E., McCain, B., Varanasi, U., 1991. Suppression of immunological memory in juvenile chinook salmon (Oncorhynchus tshawytscha) from an urban estuary. Fish Shellfish Immunol. 1, 261-277.

Arkoosh, M.R., Clemons, E., Myers, M., Casillas, E., 1994. Suppression of B-cell mediated immunity in juvenile chinook salmon (Oncorhynchus-tshawytscha) after exposure to either a polycyclic aromatic hydrocarbon or to polychlorinated-biphenyls. Immunopharmacol. Immunotoxicol. 16, 293-314.

Arkoosh, M.R., Casillas, E., Huffman, P., Clemons, E., Evered, J., Stein, J.E., Varanasi, U., 1998. Increased susceptibility of juvenile chinook salmon from a contaminated estuary to Vibrio anguillarum. Trans. Am. Fish. Soc. 127, 360-374.

Arkoosh, M.R., Clemons, E., Huffman, P., Kagley, A.N., 2001. Increased susceptibility of juvenile chinook salmon to vibriosis after exposure to chlorinated and aromatic compounds found in contaminated urban estuaries. J. Aquat. Anim. Health 13, 257-268.

Bebak-Williams, J., Bullock, G., Carson, M.C., 2002a. Oxytetracycline residues in a freshwater recirculating system. Aquacluture 205, 221-230.

Bebak-Williams, J., McAllister, P.E., Smith, G., Boston, R., 2002b. Effect of fish density and number of infectious fish on the survival of rainbow trout fry, Oncorhynchus mykiiss (Walbaum), during epidemics of infectious pancreatic necrosis. J. Fish Dis. 25, 715-726.

Begon, M., Bennett, M., Bowers, R.G., French, N.P., Hazel, S.M., Turner, J., 2002. A clarification of transmission terms in host- 
microparasite models: numbers, densities and areas. Epidemiol. Infect. 129, 147-153.

Carballo, M., Munoz, M.J., Cuellar, M., Tarazona, J.V., 1995. Effects of waterborne copper, cyanide, ammonia, and nitrite on stress parameters and changes in susceptibility to saprolegniosis in rainbow trout (Oncorhynchus mykiss). Appl. Environ. Microbiol. 61, 2108-2112.

Chou, H.Y., Chang, S.J., Lee, H.Y., Chiou, Y.C., 1998. Preliminary evidence for the effect of heavy metal cations on the susceptibility of hard clam (Meretrix lusoria) to clam birnavirus infection. Fish Pathol. 33, 213-219.

Chou, H.Y., Peng, T.Y., Chang, S.J., Hsu, Y.L., Wu, J.L., 1999. Effect of heavy metal stressors and salinity shock on the susceptibility of grouper (Epinephelus sp.) to infectious pancreatic necrosis virus. Virus Res. 63, 121-129.

Diekmann, O., Heesterbeek, J.A.P., Metz, J.A.J., 1995. The legacy of Kermack and McKendrink. In: Mollison, D. (Ed.), Epidemic Models: Their Structure and Relation to Data. Cambridge University Press, Cambridge, UK, pp. 85-115.

Forbes, V.E., Sibly, R.M., Calow, P., 2001. Toxicant impacts on density-limited populations: a critical review of theory, practice, and results. Ecol. Appl. 11, 1249-1257.

Gerber, L.R., McCallum, H., Lafferty, K.D., Sabo, J.L., Dobson, A., 2005. Exposing extinction risk analysis to pathogens: is disease just another form of density dependence? Ecol. Appl. 15, 1402-1414.

Hendriks, A.J., Maas-Diepeveen, J.L.M., Heugens, E.H.W., 2005. Meta-analysis of intrinsic rates of increase and carrying capacity of populations affected by toxic and other stressors. Environ. Toxicol. Chem. 24, 2267-2277.

Hetrick, F.M., Knittel, M.D., Fryer, J.L., 1979. Increased susceptibility of rainbow trout to infectious hematopoietic necrosis virus after exposure to copper. Appl. Environ. Microbiol. 37, 198-201.

Isshiki, T., Nagano, T., Suzuki, S., 2001. Infectivity of aquabirnavirus strains to various marine fish species. Dis. Aquat. Org. 46, $109-114$

Lafferty, K.D., Holt, R.D., 2003. How should environmental stress affect the population dynamics of disease? Ecol. Lett. 6, 654-664.

Lafferty, K.D., Kuris, A.M., 1999. How environmental stress affects the impacts of parasites. Limnol. Oceanogr. 44, 925-931.
LaPatra, S.E., 1998. Factors affecting pathogenicity of infectious hematopoietic necrosis virus (IHNV) for salmonid fish. J. Aquat. Anim. Health 10, 121-131.

Lo, C.F., Hong, Y.W., Huang, S.Y., Wang, C.H., 1988. The characteristics of the virus isolated from the gill of clam, Meretrix lusoria. Fish Pathol. 23, 147-154.

Loge, F.J., Arkoosh, M.R., Ginn, T.R., Johnson, L.L., Collier, T.K., 2005. Impact of environmental stressors on the dynamics of disease transmission. Environ. Sci. Technol. 39, 7329-7336.

McCallum, H., Barlow, N., Hone, J., 2001. How should pathogen transmission be modelled? Trends Ecol. Evol. 16, 295-300.

Murray, A.G., Peeler, E.J., 2005. A framework for understanding the potential for emerging diseases in aquaculture. Prev. Vet. Med. 67, 223-235.

Ogut, H., Reno, P.W., 2004. Effects of fish density on spread of infectious hematopoietic necrosis virus (IHNV) in rainbow trout, Oncorhynchus mykiss. Isr. J. Aquac.-Bamidgeh 25, 218-225.

Ogut, H., Reno, P.W., Sampson, D., 2004. A deterministic model for the dynamics of furunculosis in chinook salmon Oncorhynchus tshawytscha. Dis. Aquat. Org. 62, 57-63.

Ogut, H., LaPatra, S.E., Reno, P.W., 2005. Effects of host density on furunculosis epidemics determined by the simple SIR model. Prev. Vet. Med. 71, 83-90.

Sibly, R.M., Williams, T.D., Jones, M.B., 2000. How environmental stress affects density dependence and carrying capacity in a marine copepod. J. Appl. Ecol. 37, 388-397.

Sindermann, C.J., 1990. Principal Diseases of Marine Fish and Shellfish. Academic Press, Inc., New York.

Smith, K.F., Dobson, A.P., McKenzie, F.E., Real, L.A., Smith, D.L., Wilson, M.L., 2005. Ecological theory to enhance infectious disease control and public health policy. Front. Ecol. Environ. 3, 29-37.

Swinton, J., 1998. Extinction times and phase transitions for spatially structured closed epidemics. Bull. Math. Biol. 60, 215-230.

Tsoularis, A., Wallace, J., 2002. Analysis of logistic growth models. Math. Biosci. 179, 21-55. 